\title{
EAR NOSE AND THROAT CHANGES OBSERVED IN PREGNANCY IN CALABAR- NIGERIA
}

\author{
ROBERT BASSEY MGBE, ANIEFON N. UMANA, ABIOLA GRACE ADEKANYE AND \\ MBORA E. OFFIONG
}

(Received 20 April 2017; Revision Accepted 4 July 2017)

\begin{abstract}
This paper studies changes observed in pregnant women at the 3 stages of pregnancy in Calabar. Eighty pregnant women and eighty non-pregnant women were used. Most signs and symptoms occurred more in the first trimester while others occurred more in the third trimester. Vomiting, loss of appetite, excess salivation, Nausea gastro esophageal reflux, fever, headaches otomycosis were predominant in our study.
\end{abstract}

\section{INTRODUCTION}

Pregnancy is a special period of altered physiology in women. This alteration is due mainly to the secretion of hormones like oestrogen and progesterone as well as placental hormones like Human chorionic gonadotrophin (HCG), Human placental lactogen (HPL), somatomammotrophin, Human chorionic thyrotrophin (HCT) and human chorionic corticotrophin(Bhagat et al 1958,Ajiya et al 2016) These groups of hormones have a great effect on the physiology and immunological response of the body. While most of these ENT changes are temporary and will disappear after birth, some may persist.(Shiny et al 2014).It is important to anticipate these changes in view of their effects on the mother and foetus. Oestrogen and progesterone are constantly being produced and get to their peak during the third trimester. They cause changes in the ear, nose as well as the nasal, gingival and laryngeal mucosa. Cortisol on the other hand causes altered dermatological conditions and gestational immunosuppression which may lead to reactivation of latent viral infections.(Demoly et al 2003, Ellegard et al 20000) As the pregnancy progresses, the prominent nasal symptoms often will include rhnorrhoea and nasal congestion while there maybe ear symptoms like fullness, heaviness and sometimes deafness (Dekray et al 1998, Philpott et al 2004).There are also changes in gingival and laryngeal mucosa leading to effects like gingivitis, hoarseness and even in the taste buds and salivary glands causing change in taste and ptyalism. (Vandinter et al 1991, Freeman et al 1994) This paper attempts to look at the ear, nose and throat changes observed in pregnant women in Calabar.

\section{METHOD}

This is a questionnaire based prospective study carried out at the ENT clinic, University of Calabar Teaching hospital, Calabar and ante-natal clinics, General hospital Calabar. Eighty non pregnant women and eighty with pregnancy aged between 25-48 years attending the
ENT clinics of the University of Calabar Teaching Hospital and the ante-natal clinics of the General Hospital Calabar constituted the subject of this study.

Ethical clearance was sought for and obtained from the ethical committee, University of Calabar Teaching hospital, Calabar. Information on hearing loss, nasal blockage, olfactory hypersensitivity, facial palsy, nasal stuffiness, rhinorrhoea etc were inquired into. Other related conditions such as oral thrush, gingival hypertrophy were also sought. The non pregnant women were examined once while the pregnant women were examined four times; once per trimester (end of the trimester) and then four weeks post partum. Rhine's and Weber tests as well as otoscopy, rhinoscopyoropharyngoscopy were carried out and the findings recorded. Aural syringing was done in cases with excessive cerumen auris and murky debris. Written consent was obtained from voluntary participants. An author administered questionnaire was used to assess ENT symptoms.

\section{EXCLUSION CRITERIA}

Known hypertensives, diabetics, patients with HIV and AIDs in pregnancy, tuberculosis.

All pregnant women presenting after the first trimester Pregnant or non- pregnant women who refused to consent to the study.

The data collected was expressed in the form of tables and analysis was done using Epi info version 6 .

\section{RESULTS}

There were one hundred and sixty participants comprising of 80 pregnant and 80 non pregnant women. The distribution of symptoms in the pregnant group as well as those in the non pregnant group are shown in table 1 and 2 respectively. Also the distribution of symptoms according to the various trimesters is as shown in Table 3.

Robert Bassey Mgbe, ENT Department, University of Calabar Teaching Hospital, Calabar. Cross River State, Nigeria. Aniefon N. Umana, ENT Department, University of Calabar Teaching Hospital, Calabar. Cross River State, Nigeria. Abiola Grace Adekanye, ENT Department, University of Calabar Teaching Hospital, Calabar. Cross River State, Nigeria. Mbora E. Offiong, ENT Department, University of Calabar Teaching Hospital, Calabar. Cross River State, Nigeria. 
Table 1: ENT Symptoms and Signs in Pregnant Women

\begin{tabular}{|l|l|l|}
\hline Symptoms/Sign & No. of pregnant women & Percentage \\
\hline Hyperaemic tympanic memb. & 8 & 10 \\
\hline Ear blockage & 3 & 3.75 \\
\hline Hearing loss & 4 & 5 \\
\hline Murky Debris & 5 & 6.25 \\
\hline Healed perforation & 3 & 3.75 \\
\hline Turbinal Hypertrophy & 28 & 35 \\
\hline Rhinitis & 15 & 17.5 \\
\hline Olfactory sensitivity & 9 & 11.25 \\
\hline Gingival swelling & 9 & 11.25 \\
\hline Excess salivation & 50 & 62.5 \\
\hline Nausea & 30 & 37.5 \\
\hline Loss of Appetite & 20 & 25 \\
\hline Voice change & 2 & 2.5 \\
\hline Oral Thrush & 12 & 15 \\
\hline G. I. Reflux & 50 & 62.5 \\
\hline Vomiting & 60 & 75 \\
\hline Headache & 45 & 56.5 \\
\hline Fever & 40 & 50 \\
\hline Vertigo & 6 & 7.5 \\
\hline
\end{tabular}

Table 2: ENT Symptoms and Signs in Non Pregnant Women

\begin{tabular}{|c|c|c|}
\hline Symptoms/Sign & No. of women & Percentage \\
\hline Hyperaemic tympanic memb. & 3 & 3.75 \\
\hline Ear blockage & 3 & 3.75 \\
\hline Hearing loss & 4 & 5 \\
\hline Murky Debris & - & - \\
\hline Healed perforation & 2 & 2.5 \\
\hline Turbinal Hypertrophy & 7 & 8.75 \\
\hline Rhinitis & 6 & 7.5 \\
\hline Olfactory sensitivity & - & - \\
\hline Gingival swelling & - & - \\
\hline Excess salivation & 2 & 2.5 \\
\hline Nausea & - & - \\
\hline Loss of Appetite & - & - \\
\hline Voice change & - & - \\
\hline Oral Thrush & - & - \\
\hline G. I. Reflux & 6 & 7.5 \\
\hline \multicolumn{3}{|l|}{ Vomiting } \\
\hline \multicolumn{3}{|l|}{ Headache } \\
\hline \multicolumn{3}{|l|}{ Fever } \\
\hline Vertigo & 2 & 2.5 \\
\hline
\end{tabular}

Table 3: Symptoms and Signs according to Trimester

\begin{tabular}{|l|l|l|l|}
\hline Symptoms/Sign & FIRST TRIM & SECOND TRIM & THIRD TRIM \\
\hline Hyperaemic tympanic memb. & 1 & 3 & 4 \\
\hline Ear blockage & 1 & 1 & 1 \\
\hline Hearing loss & - & - & 4 \\
\hline Murky Debris & - & - & 5 \\
\hline Healed perforation & 1 & - & 2 \\
\hline Turbinal Hypertrophy & 2 & 3 & 23 \\
\hline Rhinitis & 12 & 1 & 2 \\
\hline Olfactory sensitivity & 1 & 1 & 9 \\
\hline Gingival swelling & - & - & - \\
\hline Excess salivation & 42 & 5 & 3 \\
\hline Nausea & 2 & 2 & 26 \\
\hline Loss of Appetite & 10 & 6 & 4 \\
\hline Voice change & - & - & - \\
\hline Oral Thrush & - & - & 12 \\
\hline G. I. Reflux & 2 & 13 & 35 \\
\hline Vomiting & 56 & 4 & 0 \\
\hline Headache & 30 & 12 & 3 \\
\hline Fever & 30 & 12 & 3 \\
\hline Vertigo & 6 & & \\
\hline
\end{tabular}




\section{DISCUSSION}

The distribution of symptoms is such that some of the symptoms were more pronounced during the first trimester while others manifested more in the second and third trimesters. Most of the symptoms showed up in all trimesters with various degrees of severity. In general, symptoms and signs were more in the first and third trimesters. Three pregnant participants $(3.75 \%)$ complained of ear blockage during pregnancy.

Oestrogens are known to increase nasal mucosa vascularity leading to increased nasopharyngeal gland secretions and blockage of the Eustachian tube which causes negative pressure in the middle ear with resultant symptoms of fullness, pressure, tinnitus and hearing loss present mostly during the third trimester (Dekray et al 1998, Shiny et al 2014) A similar number of non pregnant women complained of blockage. $(5 \%)$ of the pregnant women and the same $5 \%$ of the non pregnant presented with hearing loss. This figure is quite similar to that obtained in a Nigerian study (Ayyuba et al, 2016). $10 \%$ of the pregnant participants presented with hyperaemic tympanic membranes. This is expected considering the effects already stated. Hyperaemic tympanic membrane is indicative of otitis media with effusion and the number is significant compared to $(3.75 \%)$ in the non pregnant group. The presence of wax was just a normal finding as there was no difference between the percentage found in pregnant women and the non pregnant group. In the pregnant group, there were two healed perforations and on central perforation indicative of chronic suppurative otitis media. Chronic suppurative otitis media is usually a sequelae of otitis media with effusion and the three participants, $(3.75 \%)$ presenting with it in pregnancy may not mean that is commoner in pregnancy as the other group also had two healed perforations (2.5\%). Besides, the perforations may have been there long before the pregnancy.

From this study, otomycosis may be commoner during pregnancy as $(6.25 \%)$ of our pregnant participants presented with murky debris and itching in the ears suggestive of it. There was no case in the non pregnant group. Although parasympathetic effect on sweat glands is small, oestrogen alpha and betarceptors have a unique distribution in the auditory pathways (Bhagat et al 1958) and the water and electrolyte regulating regions increasing fluid availability. Besides excessive sweating in hot humid climates and in swimmers changes the $\mathrm{Ph}$ of the metal skin from that of acid to alkaline which favours growth of pathogens. (Dhingra 2007) There is also immune compromise in pregnancy aiding the emergence of otomycosis. (Anwark et al 2014)

Nasal blockage due to congestion in the inferior turbinates was observed in twenty eight pregnant participants $(35 \%)$ and seven non pregnant subjects (8.5\%) Fifteen pregnant participants (17.5\%) complained of rhinitis with clear watery rhinorrhoea during the first trimester. These nasal effects are said to be due to increase in interstitial fluid volume and direct effects of oestrogen on the nasal mucosa during pregnancy. Also, there is induced immune compromise during pregnancy enhancing the occurrence of latent diseases(Demoly et al 2003, Ellegard et al 2000) Six non pregnant participants $(7.5 \%)$ also complained of rhinitis, four of these were due to allergy. Most of the rhinitis found in the ENT clinic was due to allergy as this study suggests. In our study, hyperosmia is more common in the pregnant women as nine pregnant participants (11.25\%) and no non pregnant participant $(0 \%)$ complained of a heightened sense of smell. Hyperosmia in pregnancy is explained by the increased presence of oestrogen receptors and swelling of the olfactory membrane. Twenty pregnant participants $(25 \%)$ complained of loss of appetite, "food is no longer as pleasant" While none of the non pregnant women complained of loss of appetite. For oral lesions, no pregnant woman presented with swollen gums but white coating around the tongue indicative of oral thrush) was seen in twelve pregnant participants $(15 \%)$. This is not unconnected with the pregnancy hormones. Fifty pregnant participants $(62.5 \%)$ had excessive salivation especially in the first trimester. Only two in the non pregnant group. Thirty pregnant participants $(37.5 \%)$ complained of nausea mostly in the third trimester. There was no complaint of nausea in the non pregnant group. Fifty participants $(62.5 \%)$ complained of symptoms of gastro esophageal reflux, like epigastric pain, and peppery sensation around the chest. There were six in the non pregnant group.(7.5). G.I reflux is most pronounced during the third trimester and is attributed to decrease in oesophageal sphincter tone, increase abdominal fullness and decreased gastric emptying (Bhagat et al 1958. Bason et al 1992) Sixty (75\%) of the pregnant respondents complained of vomiting during the first trimester. This is also the effect of oestrogens during pregnancy. Forty $(50 \%)$ and forty five $(56.5 \%)$ of the pregnant women had fever and headache respectively during the first trimester. This was not our primary focus but we observed that many women complained of fever and headache; This is hardly surprising because malaria in pregnancy is quite common here. All the women with fever were tested for malaria parasites and they responded to the antimalarial drugs given to them (Eteng et al 2010).

Six $(7.5 \%)$ of pregnant women had complained of mild episodes of vertigo during the first trimester. Pregnancy worsens the vertigo in women with menieres disease (Uchide et al 1997). There was no case of a pre-pregnancy history suggestive of menieres disease in our study of eighty pregnant women. There were two cases of vertigo in the non pregnant group traceable to menieres disease.

\section{CONCLUSION}

Even though symptoms and signs observed during pregnancy are many and universal around this locality, vomiting, loss of appetite, excessive salivation, nausea, gastrointestinal reflux, fever, headaches and otomycosis seem to be predominant. Otomycosis deserves greater study.

\section{REFERENCES}

Ajiya, A., Ayyuba, R., Hamisu, A and Daneji, S. M., 2016. Otolaryngological health of women attending antenatal care in a tertiary hospital; The Aminu Kani Teaching Hospital Experience: Nig Jour Of Basic and Clinical Sciences. June-Dec, 13, (2): 
Akkoca, A. N., Ozsler, C. S., Kurt, R. K., Karapinar, O. S., Tuba, Z and Yanik, O. S., 2014. Throat Changes Observed During Three Trimesters Of Pregnancy: Science Journal Of Clinical medicine; 3, (3): 52-56.3.

Al zubaidi, A. A., 2012. Otolaryngological Manifestations In Pregnancy. Kuufa Med Journal, 15, (2):

Andre, C., 2015. Missed Opportunities to Deliver Preventive Treatment for Malaria to Pregnant Women 2003-2013; A Systemic Analysis Of 58 Household Surveys. Malasia Journal 23 Dec.

Anwark, K and Gohar, M. S., 2014. Otomycosis, Clinical Features Predisposing Factors And Treatment Implications. Pak J. Med Sci: 30; 564-7.

Bason, T. H and Richter, J. E., 1992. Gastro oesophageal Reflux During Pregnancy; Gastroenterol Clin North Am; 21:777-78.

Bhagat, R. J., Chowdary, A and Verma, S., 1958. Jyotsana; Physiological Changes In ENT During Pregnancy. Indian Otolaryngol Head Neck Surg Jul, (3): 268-270.

Demoly, P., Piette, V and Daures, J. P., 2003. Treatment of Allergic Rhinitis During Pregnancy; Drugs: 63:1813-20.

Dekray, C. S, 1998. Eustachain Tube Of Nasal Function During Pregnancy; A Prospective Study; Otolaryngol Head Neck Surgery; 99: 558-566.

Dhingra, P. L., 2007. Diseases of Ear Nose and Throat Vol $84^{\text {th }}$ Edition; Elsevier publishers Ltd; 51.

Ellegard, E., Hellgren, N., Toren, K., Karlson, G., 2000. The Incidence of Pregnancy Rhinitis; Gynaecol Obstet Invest, 49: 98-101.
Eteng, M. U and Eyong E., 2010. Biochemical And Haematological Changes In Pregnant Malaria Patients And Pregnant Non malaria Women; Scientific Research And Essays, 5, (9): 10091013.

Freeman, J. J., Alheri, R. H., Baptiste, H. J., Kao, T., Crittenden, S., Fogarty, K., Moultry, M., Coney, E and Kangis, E., 1994. Evaluation And Management Of Sialorrhoea Of Pregnancy with Concomitant Hyperemesis. J Natl Med Asso.; 86:704-708.

Gonca, S and Erol, B., 2001. Audiological Findings in Pregnancy J La 1986 ryngol Otol; 115:617-621.

Hanson, L and Abelson, S., 1986. Otolaryngological Manifestations During Pregnancy; J Fam Pract 1986; 23:151-155.

Kale, A, et al., 2015. Evaluation of Hearing And Cochlear Function By Audiometric Testing In Patients With Hyperemesis Gravidarum; The Pan African Medical Journal, 20: 231.

Philpott, C. M., Conboy, P., Alazzawi, F and Murty G., 2004. Nasal physiological changes in Pregnancy. Clin Otolaryngol Allied Sci, Aug 29: (4): 343-51.

Shiny, V and Varghese, A., 2014. ENT Changes In Pregnancy And Its Management; Indian J Otolaryngol Head Neck Surg Jan: 66 (suppl 1)

Uchide, K., Suzuki, N., Takiguchi, T., Tereda, S and Inoue, M., 1997. The Possible Effect Of Pregnancy On Menieres Disease ORL J Otolaryngol Relat Spec. 59:292-5.

Vandinter, M. C., 1991. Ptyalism In Preg women. J Obste Gynaeco IN Neonatal Nurs. 20:206-209. 


\section{QUESTIONNAIRE:}

NAME:

AGE:

SEX:

TRIBE:

ADDRESS:

RELIGION:

STAGE OF PREGNANCY: Within 3 months ( ) 3-6 months ( ) 6-9 months ( )

HEARING: has your hearing been affected during this pregnancy?: What stage? Within 3 months (-) 3-6 months ( ) 6-9 mths ( )

Which ear? (R) (L)

How serious? (slight) (moderate) (severe)

VERTIGO: Any episode of vertigo during this pregnancy? When? (before pregnancy) (1-3 months) (3-6 mths) (6-9 mths)

TINNITUS: Have you had any noise in the ear? When?

(Before pregnancy) (within 3 mths) (3-6 months) (6-9 mths)

ITCHING IN THE EARS: Any itching in your ears? Which ear? (Rt) (L). At what time?

(before pregnancy) (1-3 mths) (3-6 mths) (6-9 mths).

What other changes have you observed duringthis pregnancy?

NOSE BLEEDING: Any nose bleeds during this pregnancy? When?

(before preg) (within $3 \mathrm{mths})$ (3-6 mths) (6-9 mths)

CATARRH/BLOCKED NOSE: Have you hed nasal obstruction, stuffiness or runny nose during this pregnancy?

SMELL: Are you smelling more than before or less or as usual?

When did it change? (before pregnancy) ( within $3 \mathrm{mths})(3-6 \mathrm{mths})$ (6-9 mths)

VOICE: Is there a change in your voice? When did you notice it?

TASTE: Is there a change in your taste or appetite? When did you notice it?

SALIVATION: Are you salivating more during this pregnancy? When did it start? ( before pregnancy) (within 3 mths) (3-6 mths) (6-9 mths)

GINGIVA: Are your gums swollen? When did you notice it?

HEARTBURN: Do you have heart burn? Does it radiate to the back? When did you notice it?

OTHER CHANGES: Any other changes you have observed? Describe them. 